\title{
BICYCLES' ROLE IN ROAD ACCIDENTS A REVIEW OF LITERATURE
}

\author{
Loreta Levulyte $\dot{1}^{1}$, David Baranyai ${ }^{2}$, Ádám Török ${ }^{3}$, Edgar Sokolovskij ${ }^{4}$ \\ ${ }^{1,4}$ Vilnius Gediminas Technical University \\ Vilnius, Lithuania, J. Basanavičiaus g. 28, room $155 \mathrm{kab}$. \\ Ph.: (8 5) 274 4790,loreta.levulyte@vgtu.lt, edgar.sokolovskij@vgtu.lt \\ ${ }^{2,3}$ Budapest University of Technology and Economics \\ Budapest, Hungary, Muegyetemrkp. 3. \\ Ph.:+3614631051,torok.adam@kgazd.bme.hu, baranyai.david@mail.bme.hu
}

\begin{abstract}
Nearly 1.3 million people die in road crashes each year, on average 3,287 deaths a day. In 2013 in the European Union more than $6 \%$ of all who died in road traffic crashes were cyclists. The number of cyclist killed on roads in the EU has decreased by only $9 \%$, compared to the total fatality decrease of $18 \%$ from 2010 to 2013 . The majority of cyclist fatalities are males (78 \%). For the larger countries, Belgium and The Netherlands had the highest proportion of female cyclist fatalities (>30 \%). In general, $55 \%$ of the bicycle fatalities in the EU countries were killed inside urban areas but there are large differences between the countries. In the last couple of years there has been an enormous effort on reduction in cycling fatality numbers across almost all ages in the EU. As a result of this effort, the number of accidents started to slightly decrease.

This paper reviews the literature concerning cyclist-motor vehicle collision and road safety management according to the cyclist role in the accident rise. The paper examines pedestrians safety in order to determine what kind of factors of transport infrastructure, vehicle technical parameters, cyclist behavior and road or street category have the influence on cyclist and vehicle accidents and identify technical reasons of the accidents rise. A review is conducted of information in the literature on the injury outcome of a cyclist/vehicle collision for a given impact speed and the likely consequences of reducing the travelling speeds of vehicles in terms of the frequency and severity of cyclist injuries.
\end{abstract}

Keywords: road safety, cyclist accident, cyclist collision, accident analysis

\section{Introduction}

Cycling, as an active mode of transportation, have well-established health benefits. However, the safety of cyclists in traffic remains a major concern. In-depth studies of potential risk factors and safety outcomes are needed to ensure that the most appropriate actions are taken to improve safety (Andersen et. al., 2000; Higgins, 2005; Mueller et. al., 2015). Bicycle accident analysis require to conduct an in-depth collision analysis and identify the collision causation and contributing factors in different types of collisions, including the role of the driver(s), cyclist, vehicle(s), road-way and the environment (Thomas, DeRobertis, 2013, Jankowska et. al., 2014). The results of the accident reconstructions are useful in developing recommendations for making transport infrastructure and vehicles safer (Cao et. al., 2014). This paper is concentrated on the cyclist-vehicle collision to identify the role of cyclist in accidents and technical reasons of accidents. A cyclist, as defined for the purpose of this article, is any person on bicycle, who is involved in a motor vehicle traffic crash.

Not only from the technical view of point but also from the economical point, it is very important to understand well why people use bicycles and to identify the factors which cause accident with bicyclists. Factors that promote bicycle use are: efficiency, flexibility, economics, ecology, health, fun, but despite these there are factors that inhibit bicycle such as distance, danger, orography, fitness, climate, vandalism, facilities, and comfort. A conceptual model of the factors affecting the bicycle use can be classified in the terms of whether they are perceived as a barrier or as an incentive to bicycle use as presented in Fig. 1 (Fernández-Heredia et. al., 2014). 


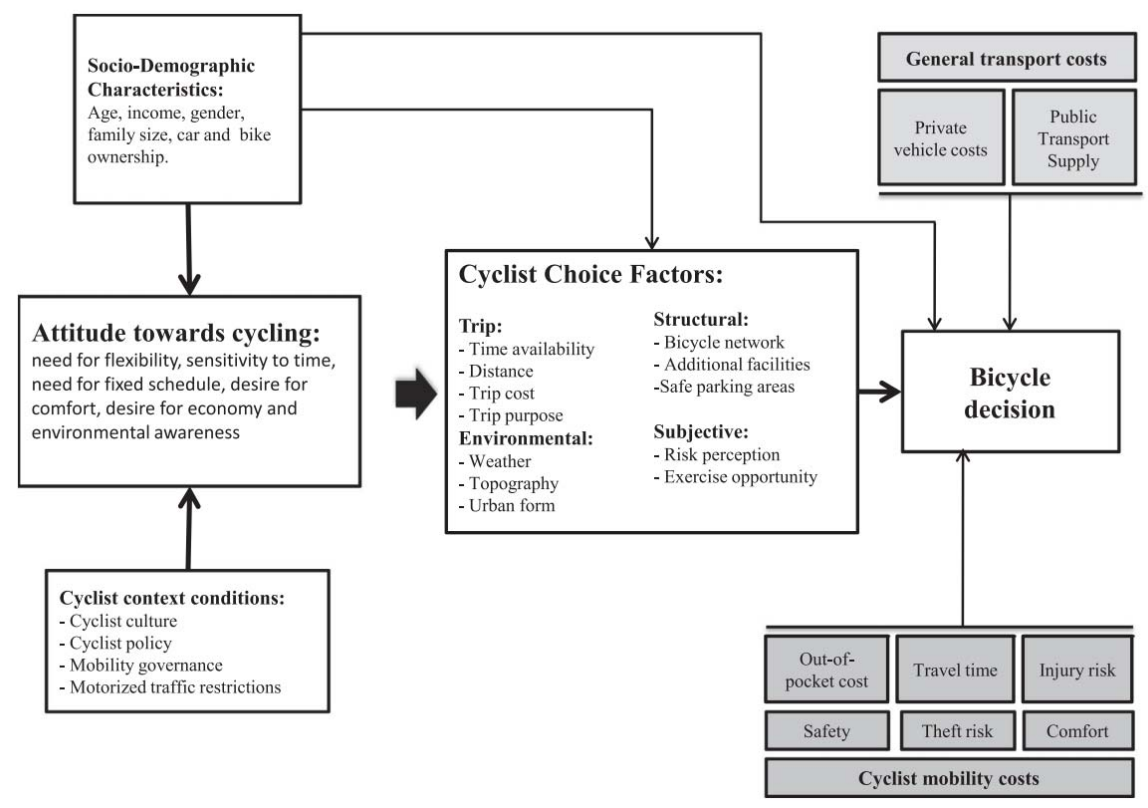

Figure 1. Conceptual model of factors affecting bicycle use (Fernández-Heredia et. al., 2014)

Cyclists are relatively unprotected road users. Schepers, Wolt (2012) indicate that about half of all single-bicycle crashes are related to the infrastructure: the cyclist rode off the road, or collided with an obstacle, the bicycle skidded due to a slippery road surface, or the rider was unable to stabilize the bicycle or stay on the bike because of an uneven road surface. When cyclists interact motorised road traffic there is a huge difference in speed and mass. Due to the differences the cyclists are more vulnerable. Cyclists suffer severe consequences in collisions with motorised road users because they can hardly protect themselves against the speed and mass of the motorised party (Piatkowski et. al. 2015). Collisions between bicyclists or motor vehicles are a major problem in the countries that are becoming motorized, and in which there are high rates of cycling (Kirolos et. al., 2015). Cyclists are commonly referred to as vulnerable road users because the lack of protective vehicle cabin. Bicycle accidents occur more frequently than indicated by police records. Bicycle helmets cannot prevent accidents but can lower head injuries therefore their wearing need to be emphasized as the only injury prevention method (Juhra et. al., 2012). Other factors, such as weather and pavement also need to be considered. Since the road conditions influence the vehicle brake way length they are very important for an accident reconstruction to determine the driver's possibility of having avoided a crash.

Most research on cyclist safety is focused on the bicycle motor vehicle crashes. According to the accident reconstruction cases there are several types of cyclist crashes. One typical crash type according to statistics was an incoming vehicle turning right across the path of a cyclist who was continuing straight. Other type of crash is connected with driving action, when the vehicle driver crossing two or more traffic lanes while undertaking the right turn maneuver. In more than half of all turning vehicles were at a signalized cross-intersection. The second most common crash scenario involving vehicles intercepting the cyclist in a $\mathrm{T}$-junction where the cyclist travelling straight on the main road. Collisions between a vehicle and a cyclist travelling in the same direction are the third most common accident cause leading to crashes. Usually vehicle driver turning left into a side street immediately ahead of the cyclist. In addition, a sideswipe collision between the right side of the passenger and the cyclist are also common (Kooijman et. al., 2011, Heesch et. al., 2011).

Protecting cyclist is a challenge, because road infrastructures typically have been built for motor vehicles (Sipos, 2014), with little attention to those who are moving on bicycle and who may wish to travel on/or alongside roads, or to cross them, or to change direction at intersections (Shinar, 2012). Nowadays, protecting cyclists is becoming more and more important. A lot of governmental institutions and scientists are working together on the vulnerable road users' protection.

\section{Procedures and Methodology}

Nowadays transport and its infrastructure play a great role in our daily life and have become a crucial component of modernity. Unfortunately, according to the crash statistics reports more and more cyclists 
are involved in traffic accidents. Transportation is being increasingly associated with the rise in road accidents and premature deaths, as well as physical and psychological handicaps. Equally significant are the rising costs in health services and the added burden on public finances. Scientists, police, investigators, road traffic accident reconstruction experts are trying to identify reasons of crashes involving cyclists (Kirolos et. al. 2015; Liu and Tung 2014; Shinar 2012).

Statistical analysis shows that $35 \%$ of cyclist fatalities in 2010 in the EU occurred in summer time, when the weather is appropriate for bicycle. The slippery wet conditions of many European winters could be connected with the high severity accidents. The likelihood of fatal accidents drops with the actual number of cyclists on the road during these seasons. It is rather influenced by the bad weather than an indication of risk avoidance improvement (Wegman, Zhang, Dijkstra, 2012).

With the aim to identify problems of cyclists on road and their behaviour, some researches use special questionnaires which sent to cyclists who had had an accident with their bicycle and were treated at Emergency Care Department (Schepers, Wolt, 2012). Some researches that analysed cyclist behaviour in traffic use conducted video observations. Such video analysis could help researchers to understand behaviour of cyclist and could help to improve legislation regarding vehicle priority (Wang, Mitani \& Yamanaka, 2012). For instance (Fabriek et. al. 2012) conducted an experiment on a closed research field where the participants' vision, in particular their contrast sensitivity, was analysed.

To create a safer cycling environment, it is necessary to understand where, when and under what circumstances bicycle accidents occur. When analysing the literature, different methodological approaches are used (Boufous et. al., 2013, Harris et. al., 2013) in order to evaluating bicycle safety. These analysed factors were mainly bicyclist ages, gender or socioeconomic status. These factors could influence traffic behaviour therefore different traffic safety guidelines may need.

Bicycle accident research papers were investigated where the cyclists' behaviour were analysed. Only English language peer reviewed papers were included in this review. The papers reporting any form of exposure measurement related to the bicycle safety have been included.

\section{Results}

After the analysis of the statistical data of the EU countries the highest percentage of the bicycle fatalities in 2010 in the Netherlands (21\%) and Hungary and Slovenia (all the three 12\%) appeared to be defined. In contrast, in Greece and Ireland, cyclists constitute only a small part (2\%) of the road accident fatalities. The majority of cyclist fatalities are males $(78 \%)$. The highest proportion of fatal female cyclist accidents Belgium was found in the Netherlands ( $>30 \%$ ), while Romania had just $7 \%$ of female fatalities in the cyclist accidents. In the EU countries, there appears to be a large proportion of cyclists of 60 years of age or older - as the society is becoming older - who die in the result of a fatal road accident (50\%). In the analysis of the age distribution of accidents in EU there appears to be a peak in fatalities of cyclists aged between 12 and 17, the age when children are more likely to undertake independent, solo cycle travels. This is a general decrease in fatality risk. Then the number of fatalities increasing again until age of 80 then there is a relatively sharp decline (Fig. 2.).

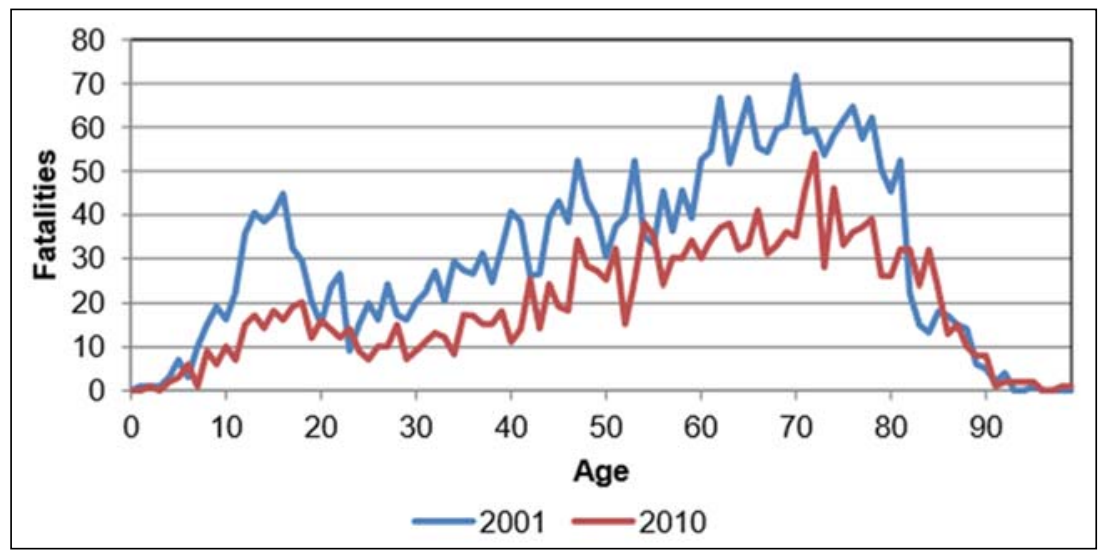

Figure 2. Ten-year comparison of cyclist fatalities by age in EU-19 countries(Data of 2009 for NL, NI and SE Source: CARE Database / EC Date of query: October 2012) 
After the analysis of the time distribution of the accidents it can be stated that the distribution of cyclists' fatalities over 24 hours in the EU countries can be described as follows. A large percentage of cyclists' fatalities across the countries occurred in the 16:00-20:00 period (28\%). Also, more bicyclists are killed in the accidents in the 08:00-12:00 and 12:00-16:00 periods (24\% and 23\% respectively) than in the other four-hour periods. Compared to other transport modes, relatively many cyclists are killed between 08:00 and 18:00 and relatively few between 22:00 and 07:00. The data analysis shows that in the EU countries almost one-third of the cyclist fatalities happened when lighting was poor (twilight or darkness). Among the worst countries, the proportion exceeded $40 \%$.

In general, $55 \%$ of the bicycle fatalities in the EU countries happened inside urban areas but there are large differences between the countries. The highest proportions of cyclist fatalities at junctions were in the Netherlands $(63 \%)$ and Germany $(51 \%)$. Focusing on cyclist fatalities at junctions, 55\% occurred at crossroads and $7 \%$ at T-junctions or staggered junctions. In Germany, the Netherlands and Poland more than $85 \%$ of cyclist fatalities at junctions occurred at crossroads. In The United Kingdom $52 \%$ of the junction cyclist fatalities occurred at T-junctions or staggered junctions. This indicates that nearly $40 \%$ of cyclist fatalities occur at junctions. Bicycles have the highest fatality rates at junctions. Fatalities with buses/coaches (Mitsakis et. al., 2015) and mopeds are the next highest frequency of fatalities occurring at junctions (32\% and 30\% respectively). In comparison, 15\% of car occupants' fatalities were at junctions. When comparing fatalities at various types of junctions with different modes of transport, it is evident that bicycle fatalities, together with buses and coaches, are over-represented at crossroads.

Speed is a fundamental risk factor in traffic. Firstly, speed is related to crash rate. From several studies of the relationship between speed and crash rate, higher speeds of individual vehicles are related to the exponential increase in crash rate. Secondly, speed is related to crash and injury severity. When the collision speed increases, the amount of energy that is released increases as well. Part of the energy will be 'absorbed' by the human body. However, the human body tolerates only a limited amount of external forces.

The number of crashes has been on the decline for years, even when the number of people commuting by bicycle increases (see Fig.3). The fatal crash numbers are so small, that the variations from year to year are probably statistically insignificant. Given the fact that the number of people riding is going up, the actual fatal crash rate is declining too. Over the years, improvements to the bicyclist safety have been made in such areas as engineering, education, enforcement and emergency response.

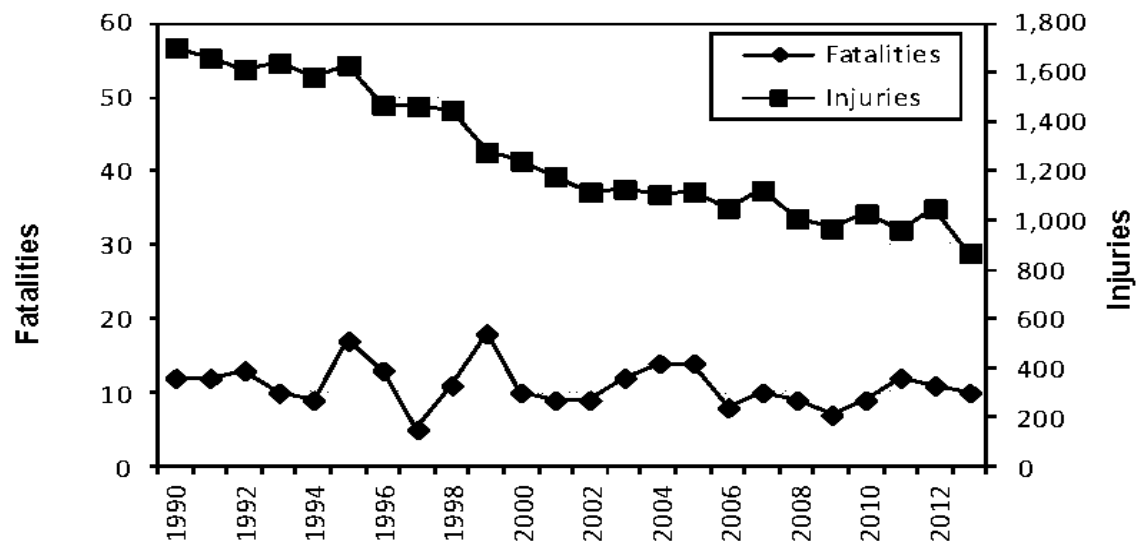

Figure 3. Bicyclist Fatalities and Injuries Source: National Safety Council

\section{Conclusion}

The need to include exposure in the bicycle safety research is being increasingly recognized, but good exposure data are often lacking, which makes the results hard to interpret and compare. Studies including exposure often use a retrospective research design, without including data on minor bicycle accidents, making it difficult to compare safety levels between age categories or against different types of infrastructure. In recent studies in which crash scenes were inspected it was found that the visual design of the infrastructure also plays a role in these crashes. The most frequent cyclist related crash type is losing control at low speed - when steering is needed for stability-, mostly while mounting or dismounting the bike. The likelihood strongly increases among elder cyclists, cyclists with physical problems and cyclists 
who have less cycling practice. Future research should focus more on children and adolescents, as this age group is a vulnerable segment of population and is underrepresented in the existing literature. Research on bicycle crashes is still in its infancy. Given the high numbers of the seriously injured victims in the countries with high amounts of cycling, more research seems to be needed to develop preventive policies. Some research questions have already been mentioned. Research can be focused on specific crash types such as crashes related to visual aspects to find certain latent causes to enable the development of countermeasures (Fabriek et. al., 2012).

\section{References}

1. Andersen, L.B., Schnohr, P., Schroll, M., Hein, H.O. (2000) All-cause mortalityassociated with physical activity during leisure time, work, sports, and cycling to work. Arch. Intern. Med. 160 (11), $1621-1628$

2. Boufous, S., de Rome, L., Senserrick, T., Ivers, R.Q. (2013) Single-versus multi-vehicle bicycle road crashes in Victoria, Australia. Inj. Prev., 19 (5): 358-362

3. Cao Y., Zuo Z., Xu H. (2014) Analysis of Traffic Conflict Characteristic at Temporary Reversible Lane., Period. Polytech. Transp. Eng., (42)1:73-76, 2014. DOI: 10.3311/PPtr.7068

4. Fabriek, E., De Waard, D., Schepers, J.P. (2012) Improving the visibility of bicycle infrastructure. International Journal of Human Factors and Ergonomics, 1:98-115.

5. Fernández-Heredia,Á., Monzón, A., Jara-Díaz, S. (2014) Understanding cyclists’ perceptions, keys for a successful bicycle promotion. Transportation Research Part A, 63:(1-11)

6. Harris, M.A., Reynolds, C.C., Winters, M., Cripton, P.A., Shen, H., Chipman, M.L. (2013) Comparing the effects of infrastructure on bicycling injury at intersections and non-intersections using a casecrossover design. Inj. Prev., 19 (5):303-310.

7. Heesch, K. C, Garrard, J., Sahlqvist, S. (2011) Incidence, severity and correlates of bicycling injuries in a sample of cyclists in Queensland, Australia. Accident Analysis and Prevention, 43 (20): 85-92.

8. Higgins, P.A.T. (2005) Exercise-based transportation reduces oil dependence, carbon emissions and obesity. Environ. Conserv. 32 (3), 197-202

9. Jankowska D., Wacowska-Slezak J., Zukowska J. (2014) Foreign visitors from Visegrad countries with regard to road safety in Poland. Period. Polytech. Transp. Eng., (42)1:77-83, DOI: 10.3311/PPtr.7250

10. Juhra, C., Wieskötter, B., Chu, K., Trost, L., Weiss, U., Messerschmidt, M. \& Raschke, M. (2012) Bicycle accidents-Do we only see the tip of the iceberg: A prospective multi-centre study in a large German city combining medical and police data. Injury, 43(12), 2026-2034.

11. Kirolos,H.; Alluri,P.; Gan, A. (2015) Analyzing Pedestrian Crash Injury Severity at Signalized and Non-Signalized Locations, Accident Analysis and Prevention 81 (0): 14-23. doi:10.1016/j.aap.2015.04.025.

12. Liu, Y. Ch.; Tung, Y.Ch. (2014) Risk Analysis of Pedestrians' Road-Crossing Decisions: Effects of Age, Time Gap, Time of Day, and Vehicle Speed, Safety Science, 63 (0): 77-82. doi:10.1016/j.ssci.2013.11.002.

13. Mitsakis E., Stamos I., SalanovaGrau J., Morfoulaki M. (2015) Bus Drivers Risk Perception of Roadway Hazards.Period. Polytech. Transp. Eng., (43)1:15-21, DOI: 10.3311/PPtr.7481

14. Mueller, N., Rojas-Rueda, D., Cole-Hunter, T., de Nazelle, A., Dons, E., Gerike, R., Goetschi, T., Panis, LI, Kahlmeier, S., Nieuwenhuijsen, M. (2015) Health impact assessment of active transportation: A systematic review. Preventive medicine, 76,103-114, ISSN: 0091-7435.

15. Piatkowski, D., Kevin P., Krizek J., Handy, S. L. (2015) Accounting for the Short Term Substitution Effects of Walking and Cycling in Sustainable Transportation, Travel Behaviour and Society 2 (1): 32 41. doi:10.1016/j.tbs.2014.07.004.

16. Schepers, J. P, Wolt, K.K. (2012) Single-bicycle crash types and characteristics. Cycling Research International, 2:119-35.

17. Shinar, D. (2012) Safety and Mobility of Vulnerable Road Users: Pedestrians, Bicyclists, and Motorcyclists. Safety and Mobility of Vulnerable Road Users: Pedestrians, Bicyclists, and Motorcyclists, 44 (1): 1-2. doi:10.1016/j.aap.2010.12.03.

18. Sipos T. (2014) Coherence between Horizontal and Vertical Curves and the Number of the Accidents. Period. Polytech. Transp. Eng., (42)2:167-172, 2014. DOI: 10.3311/PPtr.7224

19. Thomas, B., DeRobertis, M. (2013) The safety of urban cycle tracks: A review of the literature. Accident Analysis and Prevention, 52, 219-227. 
20. Wang, N., Mitani, T., Yamanaka, H. (2012) An analysis between driver's visual field and bicycle accidents or vehicle's behavior at unsignalized small intersection on the arteria road, Journal of Japan Society Of Traffic Engineering, Vol.32, No.33 (in Japanese).

21. Wegman, F., Zhang, F., Dijkstra, A. (2012) How to make more cycling good for road safety, Accident Analysis and Prevention, 44(1):19-29.

\section{Acknowledgements}

The research leading to these results has received funding from the European Union's Horizon 2020 Programme for research, technological development and demonstration under the project PROSPECT (Proactive Safety for Pedestrian and Cyclists - Grant agreement number: 634149). 